JPPUMA: Jurnal Ilmu Pemerintahan dan Sosial Politik UMA (Journal of Governance and Political Social UMA),

6 (2) (2018): 122-131, DOI: 10.31289/jppuma.v6i2.1781

JPPUMA: Jurnal Ilmu Pemerintahan dan Sosial Politik UMA

(Journal of Governance and Political Social UMA)

Available online http://ojs.uma.ac.id/index.php/jppuma

\title{
Evaluasi Program Keluarga Berencana pada Era Desentralisasi di Kuningan Jawa Barat
}

\section{Evaluation of Family Planning Programme in Decentralization Era in Kuningan West Java}

\author{
Nanang Suparman*, Fadjar Tri Sakti \& Engkus \\ Fakultas Ilmu Sosial dan Politik \\ Universitas Islam Negeri Sunan Gunung Djati Bandung, Indonesia
}

Diterima Agustus 2018; Disetujui Desember 2018; Dipublikasikan Desember 2018

\begin{abstract}
Abstrak
Program Keluarga Berencana (KB) yang dijalankan oleh pemerintah kabupaten Kuningan merupakan bagian penting dalam pelaksanaan good governance sehingga sangat layak untuk dievaluasi guna mengetahui pencapaian program yaitu membentuk keluaga kecil sejahtera melalui upaya kepedulian dan peran serta masyarakat pada aspek pendewasaan usia perkawinan, pengaturan kelahiran, dan pembinaan ketahanan keluarga, sehingga berpengaruh positif terhadap Indeks Pembangunan Manusia (IPM). Penelitian ini menganalisis empat aspek evaluasi menurut model evaluasi CIPP (Context Input Process Poduct) Stufflebeam (1991) yang meliputi aspek i) evaluasi konteks; ii) evaluasi input; iii) evaluasi proses; dan iv) evaluasi produk. Penelitian ini menggunakan metode deskriptif-kualitatif dengan data primer berupa wawancara dan data sekunder berupa dokumen yang relevan. Hasil penelitian menunjukkan adanya peran aktif masyarakat/kelompok relawan pada kegiatan pelayanan $\mathrm{KB}$, tersedianya sumber daya manusia, dana, waktu pelaksanaan, namun dengan tidak adanya indikator keberhasilan, belum adanya SOP pada evaluasi proses dan evaluasi produk maka hasil evaluasinya tidak dapat menjadi masukan yang jelas dalam siklus program keluarga berencana secara keseluruhan.
\end{abstract}

Kata Kunci: Evaluasi Program, Keluarga Berencana; Kesejahteraan Masyarakat, Pembangunan.

\section{Abstract}

The Family Planning Program (KB) run by the Kuningan district government is an important part of the implementation of good governance so it is feasible to be evaluated to find out the achievement of the program to establish a prosperous small family through caring and community participation in the maturity aspects of marriage, birth control, and fostering family resilience, which has a positive effect on the Human Development Index (HDI). This study analyzes four aspects of evaluation according to the CIPP evaluation model (Context Input Process Poduct), which includes aspects i) context evaluation; ii) evaluation of inputs; iii) process evaluation; and iv) product evaluation. This study uses a descriptive-qualitative method with primary data in the form of interviews and secondary data in the form of relevant documents. The results showed the active role of the community / volunteer groups in family planning services, the availability of human resources, funding, time of implementation, but in the absence of indicators of success, the absence of SOPs on process evaluation and product evaluation could not be a clear input. in the cycle of the overall family planning program.

Keywords: Program Evaluation, Keluarga Berencana; Community Welfare, Development.

How to Cite: Suparman, N. Sakti, F.T. \& Engkus (2018). Evaluasi Program KB pada Era Desentralisasi di Kuningan Jawa Barat. JPPUMA: Jurnal Ilmu Pemerintahan dan Sosial Politik UMA (Journal of Governance and Political Social UMA), 6 (2): 122-131.

*Corresponding author:

E-mail: n.suparman69@gmail.com
ISSN 2549-1660 (Print)

ISSN 2550-1305 (Online) 


\section{PENDAHULUAN}

Bergulirnya program Keluarga Berencana sebagai upaya pemerintah untuk menanggulangi masalah jumlah penduduk yang tidak terukur dengan pendapatan dan kebutuhan hidup serta tingkat kesejahteraan keluarga dalam perekonomian rendah. Masalah kependudukan yang dihadapi Indonesia saat ini meliputi: 1) masalah kuantitas penduduk, 2) masalah kualitas penduduk, 3) masalah mobilitas penduduk, serta masalah pendataan dan administrasi penduduk. (BKKBN, 2011:8). Pertumbuhan jumlah penduduk yang tidak terkendali akan menghambat kemajuan dan kesejahteraan suatu masyarakat, bangsa dan negara. Kondisi yang tidak seimbang antara kuantitas penduduk dengan daya dukung alam juga akan membahayakan kelangsungan hidup manusia.

Menurut UN World Population Projection (Proyeksi Populasi Dunia PBB), setiap tahun pertumbuhan penduduk alami di Indonesia sekitar 4 juta jiwa. Dengan laju pertumbuhan 1,3\% per tahun seperti yang terjadi sekarang, maka diperkirakan penduduk Indonesia akan mencapai angka 470 juta jiwa pada tahun 2060 mendatang. Akan sangat berat beban pemerintah untuk menyediakan dan memenuhi kebutuhan dasar bagi penduduk baik pangan, sandang, papan, pekerjaan, lahan, dan fasilitas publik vital lainnya seperti listrik, air bersih, sarana/pra-sarana transportasi dan lain sebagainya (BKKBN, 2011).

Lahirnya Undang-Undang No. 23 Tahun 2014 tentang Pemerintahan Daerah memberi angin segar bagi kinerja organisasi Badan Koordinasi Keluarga Berencana Nasional (BKKBN), khusunya di daerah, karena setiap urusan pemerintahan yang menyangkut daerah diserahkan kepada pemerintah daerah (desentralisasi).

Turner dan Hulme dalam Engkus, (2013), berpendapat lain, dalam tataran implementasi terdapat 5 (lima) hal penting yakni: 1) Devolusi, 2) Incrementalism, 3) Centralization, 4). Irrelevance, dan Kontingensi. Dalam kajian administrasi publik bahwa desentralisasi akan mendorong keputusan yang lebih baik dan karenanya meningkatkan efisiensi dan efektivitas berdasarkan argumen: Perencanaan berbasis kebutuhan lokal, koordinasi antar organisasi tingkat lokal, memacu inovasi lokal, meningkatkan motivasi dan kompetensi Sumber Daya Manusia dan pengurangan beban kerja pemerintah pusat dalam tataran implementasi.

Dengan adanya otonomi daerah, kebijakan kependudukan dan Keluarga Berencana (KB) menghadapi tantangan luar biasa berat, karena secara kelembagaan di tingkat Kabupaten /Kota antara ada dan tiada. hal ini disebabkan belum semua pemerintahan di daerah memiliki pandangan yang sama tentang arti pentingnya kependudukan dan Keluarga Berencana, sejatinya otonomi darah menurut Suparman (2017) dimaksudkan untuk memberi ruang kreasi kepada Pemerintah Daerah untuk terciptanya pelayanan publik yang lebih baik dan peningkatan kesejahteraan masyarakatnya. Namun, di seluruh Indonesia jumlah petugas Keluarga Berencana yang ada di lapangan semakin berkurang cukup drastis dari sebelumnya berjumlah $30 \mathrm{ribu}$, kini hanya tinggal 21 ribu petugas. Padahal petugas lapangan Keluarga Berencana ini merupakan tombak yang menjembatani antara kebijakan yang dikeluarkan dan operasionalisasi di lapangan sehingga pelaksanaan program Keluarga Berencana seringkali tidak efektif.

Pada era otonomi daerah ini program apapun termasuk program KB yang berdimensi pelayanan pada masyarakat dituntut untuk berkualitas. Suparman (2017) menyebutkan bahwa pelayanan publik sejatinya diharapkan oleh masyarakat pengguna layanan dalam 
bentuk dan delivery yang prima dalam arti pelayanan yang mudah, cepat, tepat, dan aman ditandai oleh pelayanan yang tidak berbelit-belit, pelayanan yang wellinformed, responsive, akomodatif, konsisten, dan adanya kepastian (waktu,biaya,hukum) dan tidak dijumpai pungutan tidak resmi itulah diantaranya penerapan prinsip pelayanan prima dalam metode dan prosedur yang erat dengan kebijakan publik (public policy).

Pemerintah Kabupaten Kuningan mendukung pelaksanaan Pembangunan Nasional yang telah ditetapkan Pemerintah Pusat pada bidang Keluarga Berencana dengan Visi "penduduk seimbang tahun 2015" dengan misi "mewujudkan pembangunan yang berwawasan kependudukan dan mewujudkan keluarga kecil bahagia dan sejahtera. Sesuai dengan Peraturan Pemerintah (PP) No. 38 tahun 2007 bahwa urusan pemerintahan bidang Keluarga Berencana merupakan urusan wajib yang harus dilaksanakan oleh pemerintah daerah maka urusan pemerintahan tersebut perlu diatur melalui kebijakan publik pemerintahan tingkat lokal sesuai dengan Norma, Standar, Prosedur, Kriteria yang telah ditetapkan. Kabupaten Kuningan mewujudkan kebijakan tersebut dengan menerbitkan Peraturan Bupati Nomor 23 Tahun 2008 tentang tugas pokok, fungsi dan uraian tugas pada Lembaga Teknis Daerah dimana bidang Keluarga Berencana ada di Dinas Pengendalian Penduduk dan Keluarga Berencana (DPPKB) yang salah satu tugas pokoknya adalah mengevaluasi perencanaan dan pelaksanaan kebijakan daerah bidang Keluarga Berencana.

Kegiatan program Keluarga Berencana Nasioanal yang dilaksanakan di kabupaten Kuningan berdasarkan data dan informasi yang diperoleh dari Review Program Keluarga Berencana Tahun 2015, serta pengamatan pendahuluan terdapat beberapa permasalahan yang ditemukan yaitu: Alat kontrasepsi suntik dalam satu tahun mengalami beberapa kali kekosongan. Capaian Peserta Baru (PB) tidak memberikan kontribusi terhadap Peserta Aktif (PA), ditemukan adanya beberapa perubahan cara dari metode kontrasepsi jangka panjang menjadi metode kontrasepsi jangka pendek, ada anggapan program Keluarga Berencana tidak begitu penting karena merupakan program lama, Pemerintah Daerah belum memberikan dukungan sumber daya manusia yang mencukupi sehingga mempengaruhi gerak operasional dalam program Keluarga Berencana, evaluasi program belum fokus pada capaian program, kemudian evaluasi yang dilakukan cenderung bersifat formatif dan hanya menekankan pada aspek-aspek administrasi keuangan, sebagai akibat belum fokusnya evaluasi program maka evaluasi yang dilakukan selama ini tidak dapat mengungkap kondisi para penerima (akseptor) atau pemanfaat dari masingmasing program Keleuarga Berencana.

Berdasar pada uraian latar belakang di atas, maka evaluasi program Keluarga Berencana di Kabupaten Kuningan merupakan bagian penting dalam pelaksanaan good governance sangat layak untuk dievaluasi guna mengetahui sejauh mana evaluasi program keluarga berencana telah mampu mencapai tujuan program yaitu membentuk keluarga kecil sesuai dengan kapasitas sosial ekonomi suatu keluarga dengan cara pengaturan kelahiran anak, agar dipeoleh suatu keluarga bahagia dan sejahtera yang dapat memenuhi kebutuhan hidupnya.

\section{METODE PENELITIAN}

Penelitian ini dilaksanakan di Dinas Pengendalian Penduduk dan Keluarga Berencana (DPPKB) Kabupaten Kuningan. Pemilihan lokasi ini didasarkan karena Kabupaten Kuningan merupakan kategori kota dengan karakteristik persebaran penduduk yang khas di Jawa Barat dan mempunyai permasalahan daya serap tenaga kerja yang terbatas sehingga upaya 
pengendalian masalah kuaniitas penduduk menjadi hal yang sangat penting.

Penelitian ini dengan desain kualitatif-deskriptif dengan tujuan untuk mendapatkan data empirik tentang komponen-komponen yang melatarbelakangi evaluasi program di DPPKB Kabupaten Kuningan. Data primer diperoleh melalui wawancara terhadap para pejabat struktural, PLKB, dan para pegawai yang berkaitan. Adapun data sekunder diperoleh melalui kajian dokumen yang dikaji untuk sementara akan difokuskan pada program kerja, struktur organisasi, rencana strategis, Job description, laporan-laporan kegiatan internal DPPKB, dan kegiatan-kegiatan antar dinas di Pemerintah Kabupaten Kuningan. Data atau bahan-bahan yang diambil antara lain: Surat Keputusan, Peraturan Daerah Kabupaten Kuningan, Peraturan Bupati Kabupaten Kuningan, Rencana Strategis, Rencana Kerja, Profil DPPKB, dan ruang lingkup pekerjaan.

\section{HASIL DAN PEMBAHASAN \\ Evaluasi Konteks Program Keluarga Berencana}

Evaluasi konteks mengacu pada kekuatan dalam pelaksanaan Program KB diantaranya adanya dukungan dari pemerintah baik itu dari Pemerintah Kabupaten Kuningan maupun Pemerintah Provinsi Jawa Barat. Berbagai kegiatan yang diselenggarakan di masyarakat menunjang keberhasilan program KB yaitu Pelaksanaan Bina Keluarga Balita di RW VI Kelurahan Kuningan Kota pada pelaksanaan kegiatan Bina Keluarga Balita dihadiri oleh petugas PLKB l (satu) orang, Kader 3 orang, Tenaga Penggerak Desa 1 (satu) orang, Ibu Balita beserta Balita sebanyak 20 orang, Kelompok Bina Keluarga Balita (BKB) merupakan salah satu bentuk kelompok kegiatan yang menjadi salah satu program unggulan BKKBN, dimana Bina Keluarga Balita adalah kegiatan yang khusus mengelola tentang pembinaan tumbuh kembang anak melalui pola asuh yang benar berdasarkan kelompok umur, yang dilaksanakan oleh sejumlah kader dan berada ditingkat RW. (Pedoman Pembinaan Kelompok Bina Keluarga Balita Tahun 2016).

Pelaksanaan kegiatan posyandu dilakukan oleh kader kesehatan yang berasal dari masyarakat setempat, dengan bimbingan dari lintas sektor terkait seperti tim penggerak PKK, Dinas Kesehatan dan Puskesmas, serta Badan Pemberdayaan Masyarakat Pemberdayaan Perempuan dan Keluarga Berencana. Sasaran kegiatan posyandu adalah semua masyarakat, terutama bayi, balita, ibu hamil, dan ibu menyusui. Waktu dan tempat pelaksanaan posyandu ditentukan oleh masyarakat sendiri. Kelengkapan sarana pendukung sangat penting bagi sebuah posyandu karena dapat meningkatkan kinerja kader dalam melaksanakan kegiatan posyandu. Berdasarkan wawancara dengan kader, sarana pendukung yang terdapat di posyandu ialah timbangan, buku register posyandu dan papan nama posyandu. Salah satu kegiatan revitalisasi posyandu adalah pemberdayaan tokoh masyarakat, pemberdayaan kader melalui pelatihan, penyegaran, jambore, dan cerdas cermat, serta pengadaan alat masak dan kebutuhan operasional. Oleh sebab itu, tujuan khusus program ini ialah agar tercapainya pemberdayaan tokoh-tokoh masyarakat dan kader posyandu sehingga kegiatan rutin posyandu dapat terselenggara dengan baik dan gizi anak serta kesehatan ibu dapat ditingkatkan. Secara umiun istilah kader kesehatan yaitu kader-kader yang dipilih oleh masyarakat tadi menjadi penyelenggara Posyandu. Dalam rangka mensukseskan pembangunan nasional, khusus dibidang kesehatan, bentuk pelayanan kesehatan diarahkan pada prinsip bahwa masyarakat bukanlah sebagai objek akan tetapi merupakan subjek dari pembangunan itu sendiri. Posyandu diharapkan dapat meningkatkan kegiatan program UKBM sebagai upaya penggerakan dan 
pemberdayakan masyarakat. Upaya ini merupakan strategi yang bertujuan mempercepat pencapaian derajat kesehatan masyarakat yang setinggitingginya. Melalui pemberdayaan ini diharapkan masyarakat mampu mandiri dan menyelesaikan masalah kesehatannya sendiri.

Upaya penggerakan masyarakat dapat terwujud bila semua lintas program dan lintas sektor serta masyarakat memahami tanggung jawab, tugas dan fungsinya. Untuk itu diperlukan peningkatan pemahaman, pengetahuan dan kemampuan lintas sektor/lintas program serta masyarakat, kegiatan pembinaan Kader Posyandu menjadi wahana yang menjembatani antara kebutuhan program dan proses kemandirian masyarakat. Di dalam pemberdayaan masyarakat yang terpenting adalah bagaimana menjadikan masyarakat pada posisi pelaku pembangunan yang aktif dan bukan penerima pasif. Dengan demikian berarti keberhasilan perencanaan dan pelaksanaan program sangat ditentukan oleh partisipasi aktif dari seluruh masyarakat.

\section{Evaluasi Input Program Keluarga Berencana}

Evaluasi input untuk mengaitkan tujuan, konteks, input, proses dengan hasil program. Evaluasi ini juga untuk menentukan kesesuaian lingkungan dalam membantu pencapaian tujuan dan objektif program. Selain itu, evaluasi ini dibuat untuk memperbaiki program bukan untuk membuktikan suatu kebenaran. Evaluasi input dilakukan terhadap tersedianya sumber daya program dalam hal ini Anggaran, Sumber Daya Manusia dan sarana prasarana yang digunakan. Anggaran yang tersedia untuk program KB yaitu untuk pencapaian sasaran 1 yaitu meningkatnya peran aktif masyarakat/ kelompok/organisasi dalam Program KB, sebagai input dibutuhkan anggaran sebesar Rp. 2.227.189.500,-. Dalam realisasi pelaksanaannya, target output tercapai $100 \%$ dengan realisasi anggaran sebesar Rp. 2.212.403.500,-. Oleh karena itu terjadi efisiensi sebesar 1,20\%. Upaya untuk meningkatkan peran aktif masyarakat/kelompok/organisasi dalam Program KB, dilakukan melalui Program Keluarga Berencana yang terdiri dari 3 kegiatan yaitu Kegiatan Promosi Pelayanan KHIBA, Kegiatan Pembinaan Keluarga Berencana, dan Kegiatan Pelayanan KIE, serta Program Kesehatan Reproduksi Remaja yaitu kegiatan Advokasi dan KIE tentang Kesehatan Reproduksi Remaja.

Sumber Daya Manusia dalam hal ini Petugas Lapangan Keluarga Berencana (PLKB) sebanyak 16 (enam belas) orang membawahi 115 Desa, setiap PLKB memegang 3-4 Desa. Dengan adanya Tenaga Penggerak Desa (TPD) sebanyak 27 orang yang dibiayai oleh Pemerintah Provinsi Jawa Barat hal ini merapakan peluang untuk menutupi tenaga PLKB yang jumlahnya terbatas. Hal tersebut selaras dengan pendapat R. Terry bahwa manajemen merupakan suatu proses khas yang terdiri dari tindakan-tindakan perencanaan, pengorganisasian, penggerakan dan pengendalian yang dilakukan untuk menentukan serta mencapai sasaran yang telah ditentukan melalui pemanfaatan sumberdaya manusia dan sumberdaya lainnya. Selain tenaga PLKB dalam pelaksanaan program KB di lapangan dibantu oleh Pos Keluarga Berencana (PKB) sebagai bagian dari sub sistem keberhasilan program KB, Pos KB merupakan ujung tombak yang berperan dalam mensosialisasikan sekaligus menjabarkan visi misi program KB dan KS (Keluarga Sejahtera) di tingkat lini lapangan. Mereka adalah "ujung tombak" pelaksanaan program KB di daerah baik tingkat kabupaten, kecamatan, kelurahan maupun desa bahkan hingga pada mobilisasi dan sosialisasi pada masyarakat secara langsung. Dukungan nyata lainnya dari petugas KB di lapangan adalah mulai 
dari penggerakan kegiatan, pengelolaan dan pelaksanaan sampai pada pengumpulan data basis melalui pendataan keluarga yang setiap tahun dilaksanakan. Secara manajerial, PKB mempunyai 6 (enam) fungsi dan tugas, yaitu fungsi merencanakan, mengorganisasikan, melaksanakan, mengembangkan, melaporkan, dan mengevaluasi Program KB Nasional dan program pembangunan lainnya di wilayah binaan nya (BKKBN, 2002).

\section{Evaluasi Proses Program Keluarga Berencana}

Evaluasi proses yang dilakukan adalah untuk melihat seberapa jauh kegiatan yang dilaksanakan sudah terlaksanan sesuai rencana, seperti yang disampaikan oleh Informan bahwa: "Evaluasi proses dilakukan, dengan melihat target akseptor baru dari BKKBN Pusat disesuaikan dengan bentuk kegiatan yang ada di dokumen pelaksanaan anggaran, misalnya target pemasangan IUD 100, kita punya kegiatan dalam rangka pelayanan IUD, pelayanan IUD dengan target IUD disesuaikan, kita laksanakan".

Pelaksanaan kegiatan tersebut dilakukan melalui kegiatan TKBK (Tim KB Keliling) ada satu wilayah di masingmasing kecamatan, daerah cekungan misal di RW 6 Desa Mekar Sari, semua petugas di Kecamatan Cilimus turun ke daerah tersebut dari mulai PLKB, TPD, Pos KB dan Sub Kelompok Akseptor menggarap wilayah yang merupakan daerah cekungan pencapainnya rendah, pra KS banyak, sasaran banyak, kemudian digarap bersama-sama, muncul calon akseptor, dibawa ke kegiatan pelayanan yang ada, hal tersebut itu merupakan salah satu proses kegiatan yang dilakukan.

Kegiatan TKBK merupakan program rutin Bidang $\mathrm{KB}$ dalam rangka terus meningkatkan peran serta masyarakat dalam ber KB. TKBK merupakan satuan kerja terpadu yang terdiri dari pelayanan kontrasepsi, penyuluhan, pengendalian lapangan. dan kegiatan integrasi KB dengan pembangunan lainnya. Tujuan diadakannya TKBK untuk menyelaraskan keterpaduan gerak komponen $\mathrm{KlE}$ dan pelayanan ontrasepsi serta kegiatan lain yang mendukung program KB. Prinsip pelaksanaan diarahkan pada wilayah prioritas sasaran yang digarap. Salah satu Informan menyampaikan bahwa: "Ada yang namanya pertemuan Sub dilakukan setiap bulan, yang dihadiri oleh PLKB, Pos KB, Sub KB di pertemuan tersebut dibahas tentang pendataan, data didapat dari kader di tingkat RW, namanya R1 Sub, data dari tingkat RW masuk ke tingkat kelurahan namanya Rl Dal, Rl dal tingkat kecamatan masuk ke tingkat kota, nah itu termasuk evaluasi proses".

Dalam rangka mengembangkan jaringan operasional KB sampai ke tingkat RW dan RT peran serta institusi masyarakat dalam wujud Pos KB dan sub Pos KB dan kelompok akseptor sangat menentukan pelaksanaan program KB. Di era sekarang ini, khususnya di era otonomi daerah, peran Pos KB dan Sub Pos KB penting dan menjadi satu kekuatan yang dapat diandalkan untuk tetap dapat mempertahankan keberhasilan program KB di masyarakat seiring dengan terus menurunnya jumlah Penyuluh KB yang aktif karena pindah, pensiun atau meninggal. Pettigas Pos KB dan Sub Pos KB menjangkau seluruh RT dan serta memiliki daya juang yang tinggi dalam rangka ikut mensukseskan program KB.

Evaluasi proses merupakan sumber informasi penting untuk menafsirkan hasil evaluasi produk. Hasil pengamatan di lapangan menunjukkan pelaksanaan program dilaksanakan sesuai dengan rencana pelaksanaan baik dari sisi jadwal maupun pelaksana program mampu menangani kegiatan selama program berlangsung, hanya untuk sarana dan prasarana yang tersedia seperti penggunaan mobil penerangan belum digunakan secara maksimal.

Hasil wawancara yang dilakukan di Puskesmas Cigugur bahwa sarana 
prasarana untuk pelayanan KB bagi keluarga miskin terutama IUD dan PIL mencukupi, sedangkan suntik beberapa kali mengalami kekosongan sehingga pada saat mengalami kekosongan untuk sementara waktu diganti dengan Pil. Pada pelaksanaannya peserta KB yang berasal dari keluarga miskin tidak dipungut bayaran sedangkan untuk pasien umum dipungut bayaran sesuai dengan Peraturan Daerah, untuk pemasangan IUD Rp.50.000, Implant

Rp. 75.000, Cabut Implant Rp.90.000, Suntik Rp. 5.000, dan PIL gratis. Pada pasien yang berasal dari keluarga miskin masih banyak yang menggunakan alat kontrasepsi pil dan suntik.

Sering terjadinya kekosongan alat kontrasepsi suntik merupakan kelemahan dari program KB karena ketersediaan sarana prasarana dan alat-alat kontrasepsi di semua sarana pelayanan kesehatan menjadi hal yang sangat penting, pada penggunaan metode kontrasepsi jangka pendek tingkat putus-pakai tinggi. Untuk mengatasi masalah tingkat putus-pakai tinggi diperlukan adanya revitalisasi Program KB untuk penguatan supply dan demand secara seimbang. Dalam penguatan supplyside, jajaran Kementerian Kesehatan, BKKBN, dan Pemerintah Daerah bersama masyarakat melakukan dengan sungguh-sungguh, sesuai dengan tugas pokok dan fungsinya, upaya-upaya yang mencakup memperkuat sistem pelayanan $\mathrm{KB}$, memperkuat kerja sama dengan mitra pelayanan Program KB, memastikan ketersediaan saranaprasarana dan alat-obat kontrasepsi di semua sarana pelayanan kesehatan, meningkatkan kapasitas provider pelayanan KB. (BKKBN, 2013)

Revitalisasi menjadi penting karena realitas di lapangan menunjukkan pencapaian peserta baru (PB) tidak memberikan kontribusi terhadap peserta aktif (PA). PB juga tidak memberikan dampak signifikan terhadap unmet need, Berdasarkan Laporan Tahunan Tahun
2012 angka unmet need sebanyak $11 \%$ sedangkan tahun 2013 angka unmet need sebanyak $10,3 \%$. Setelah ditelisik, ternyata pemicunya terletak pada komposisi peserta KB yang didominasi kontrasepsi jangka pendek dengan tingkat putus-pakai tinggi. Keberadaan perempuan Unmet need menurut Lalu Makripuddin (2011): Keberadaan perempuan unmet need mehunjukkan bahwa pelaksanaan program, belum mampu memenuhi seluruh permintaan masyarakat akan keluarga berencana. Upaya mengatasinya seyogyanya dengan cara komprehensif.

Tingginya putus-pakai alat atau obat kontrasepsi dipicu beberapa hal. Sebut saja misalnya lemahnya pembinaan dan pemberian kontrasepsi ulangan, sistem rujukan dan distribusi kontrasepsi belum berjalan sebagaimana mestinya, dan terbatasnya tenaga kompeten dalam memberikan pelayanan metode kontrasepsi jangka panjang (MKJP). (Kencana, 2013). Hasil analisis situasi oleh BKKBN dan UNFPA menunjukkan lemahnya kemampuan tenaga dan kerangka kerja merupakan kendala terbesar untuk menciptakan efektivitas pelaksanaan program KB di kabupaten dan kota. Komponen supply berupa penguatan subsistem pemberian pelayanan-pelatihan, supervisi, logistik, dan rujukan. Ini akan meningkatkan jumlah dan ketersediaan tenaga pelayanan KB yang terampil, berpengetahuan baik, termotivasi, dan terdukung secara memadai. Kelemahan dari Program KB selain ditemukannya kekosongan alat kontrasepsi jenis suntik juga masih adanya pemahaman di masyarakat yang mengatakan banyak anak banyak rejeki, dan Program KB dianggap bukan merupakan hal yang penting karena merupakan program lama.

\section{Evaluasi Produk Program Keluarga Berencana}

Evaluasi produk untuk mengukur pencapaian program dilakukan secara rutin setiap satu bulan sekali, dibadiri oleh 
PLKB, TPD (Tenaga Penggerak Desa), struktural dan bidang-bidang terkait, bidang Pemberdayaan Perempuan, Bidang Pemberdayaan Masyarakat. Dalam evaluasi tersebut yang dilakukan di kantor kami dilakukan 11 kali, kemudian dilakukan 1 tahun sekali melalui rakerda, yang satu bulan 1 kali lainnya laginya dilakukan melalui pertemuan Sub PPKBD dilakukan di masing-masing kelurahan. Evaluasi produk dilakukan setiap selesai melakukan kegiatan, setiap 1 bulan satu kali, laporan triwulanan dan laporan tahunan.

Adapun pencapaian produk terhadap target perencanaan program dan kegiatan yang telah ditetapkan, diukur berdasarkan indikator kinerja dan dilakukan evaluasi Program KB, yakni kegiatan penyediaan penyediaan pelayanan $\mathrm{KB}$ dan alat kontrasepsi bagi keluarga miskin sebanyak 1.190 akseptor. Kegiatan penyediaan penyediaan pelayanan $\mathrm{KB}$ dan alat kontrasepsi bagi keluarga miskin harus terlayani secara gratis sedangkan bagi masyarakat yang mampu ber KB secara Mandiri, KB diharapkan mampu memutus lingkaran kemiskinan, di mana para akseptor kalangan masyarakat kurang mampu, diberikan subsidi (alat) KB yang berkelanjutan secara gratis. Apalagi dengan program KB gratis, keluarga yang tadinya miskin dapat merencanakan masa depan sang anak tanpa harus berlarut terjerumus di tengah kesulitan ekonomi keluarga. Jika keluarga miskin hanya memiliki anak dua atau maksimal tiga dengan jarak yang teratur atau anak pertama ke anak berikutnya berjarak sekitar tiga tahun, tentunya kesulitan ekonomi (terkait pembiayaan) tidak akan begitu terasa. Karenanya, dalam menyukseskan Program KB saat ini, pemerintah terfokus pada alat kontrasepsi yang murah, namun berkelanjutan, atau berfungsi hingga jangka waktu cukup lama yang nantinya diberikan secara gratis ke kalangan masyarakat kurang mampu. Jika masyarakat miskin dipaksa menggunakan kontrasepsi mahal, baik berupa pil atau pun suntik KB. Dua program ini selain mahal biayanya, bahkan hanya memiliki batasan waktu yang singkat. Dengan program KB menggarap kalangan miskin ini, diharapkan lingkaran kemiskinan dapat diputuskan secara generative.

Pelayanan KIE sebanyak 82 kali. Pelayanan KIE, Komunikasi adalah penyampaian pesan secara langsung ataupun tidak langsung melalui saluran komunikasi kepada penerima pesan, untuk mendapatkan suatu efek (DEPKES RI, 1984). Informasi adalah keterangan, gagasan, maupun kenyataan-kenyataan yang perlu diketahui oleh masyarakat (BKKBN, 1993). Edukasi adalah proses perubahan perilaku kearah yang positif (DEPKES RI, 1990). Tujuan dilaksanakannya program KIE, yaitu: 1) Meningkatkan pengetahuan, sikap dan praktik KB sehingga tercapai penambahan peserta baru. 2) Membina kelestarian peserta KB. 3) Meletakkan dasar bagi mekanisme sosio cultural yang dapat menjamin berlangsungnya proses penerimaan. 4) Untuk mendorong terjadinya proses perubahan perilaku kearah yang positif, peningkatan pengetahuan, sikap dan praktik masyarakat (klien) secara wajar sehingga masyarakat melaksanakannya secara mantap sebagai perilaku yang sehat dan bertanggung jawab.

Pembinaan Keluarga Berencana antara lain Bina Keluarga Balita sebanyak 172 kelompok, Bina Keluarga Remaja sebanyak 88 kelompok., Bina Keluarga Lansia sebanyak 145 kelompok, dan kelompok kegiatan UPPKS 40 kelompok. Keberadaan Keluarga Berencana (KB) tidak terbatas hanya untuk membatasi kelahiran. KB harus diarahkan agar pesertanya bisa membina dan mencapai keluarga yang sejahtera. Haryono Suyono (2008): KB merupakan salah satu sarana untuk menciptakan keluarga sejahtera. Pada dasarnya keberadaan KB tidak hanya untuk mengurangi kepadatan penduduk. 
Untuk itu, sudah saatnya program KB sekarang dioptimalkan untuk meningkatkan kesejahteraan keluarga. Pembangunan bidang kependudukan dan KB merupakan investasi jangka panjang. Karena itu, selain peningkatan kemandirian, harus diupayakan pula peningkatan pemahaman. KB tidak saja bermanfaat untuk pengaturan kelahiran, namun juga untuk peningkatan derajat kesehatan ibu dan anak. KB juga bermanfaat bagi peningkatan kualitas generasi mendatang. Untuk mendukung terwujudnya keluarga sejahtera harus dilakukan upaya melalui program Ketahanan dan Pemberdayaan Keluarga. Hal itu bisa dilakukan dengan cara menggerakkan kelompok kegiatan Catur Bina, yaitu Bina Keluarga Balita (BKB), Bina Keluarga Remaja (BKR), Bina Keluarga Lansia (BKL), dan Bina Lingkungan Keluarga (BLK). Pembentukan kelompok-kelompok ini dimaksudkan guna meningkatkan pengetahuan, sikap, dan perilaku keluarga dalam melakukan pengasuhan dan menumbuhkembangkan anak balita, pembinaan menumbuhkembangkan remaja, pembinaan lansia, dan pembinaan peningkatan kualitas lingkungan keluarga. Kelompok-kelompok ini bisa dikembangkan sehingga mampu menjadi kekuatan pembangunan. Menurut Haryono Suyono, ada tiga faktor utama untuk mengentaskan kemiskinan, yakni faktor manusia, wirausaha, dan lingkungan.

\section{SIMPULAN}

Berdasarkan hasil penelitian, bahwa evaluasi program keluarga berencana di Kabupaten Kuningan, selama ini tidak mencantumkan indikator keberhasilan pada semua aspek evaluasi terkecuali pada evaluasi konteks. Dengan evaluasi yang tidak jelas tersebut, maka tidak dapat mengungkap kondisi para penerima atau pemanfaat dari masing-masing program keluarga berencana. Dengan demikian, dapat dikatakan bahwa evaluasi program keluarga berencana yang dilakukan belum dapat dikatakan baik karena secara teoritis menurut Stufflebeam bahwa evaluasi program merupakan 4 (empat) rangkaian sistemik meliputi konteks, input, proses, dan produk yang tertera dalam kegiatankegiatan yang ada saling berkaitan, sedangkan dalam evaluasi program keluarga berencana dengan tidak adanya indikator keberhasilan, evaluasi proses belum adanya Standard Operating Procedure (SOP) dan evaluasi produk hasil evaluasinya tidak dapat menjadi masukan yang jelas dalam siklus program keluarga berencana secara keseluruhan.

\section{DAFTAR PUSTAKA}

Anderson, J.E. (2000). Public Policy Making, $4^{\text {th }}$ Ed., Berkeley, Boston, USA: Houghton Mifflin Co.

Badan Badan Kependudukan Keluarga Berencana Nasional.(2010). Gerakan KB Nasional. http://www.bkkbn. go. id

Badan Kependudukan Keluarga Berencana Provinsi Jawa Barat. (2010) Ulasan Ringkas Hasil Pendataan Keluarga. Bandung: BKKBN.

Badan Koordinasi Keluarga Berencana Nasional. Program KB Nasional Era Desentralisasi. http://www.bkkbn.go.id (12 Oktober 2006)

Darwin, M dan Kutanegara, P.M. (2010). Dinamika Kependudukan dan Penguatan Governance. Yogyakarta: Media Wacana.

Departemen Kesehatan. (2006). Modul Pelatihan Pengarus Utamaan Gender. Jakarta: Departemen Kesehatan.

Engkus. (2013). Desentralisasi (Teori Yang baik deangan Praktek Yang Buruk). JISPO: Jurnal Ilmu Sosial dan Ilmu Politik. 3(1): 1-16.

Faturohman \& Wicaksono, B (Eds). (2004). Dinamika Kependudukan dan Kebijakan. Yogyakarta: Pusat Studi Kependudukan dan Kebijakan Universitas Gadjah Mada.

Frederick-son, G.H. \& Smith, K.B. (2003). The Public Administration Theory Primer. West View Press.

Goldman. M.B. \& Hatch M.G. (2000). Women and Health. San Diego: Academic Press.

Handayani, S. (2010). Pelayanan Keluarga Berencana. Yogyakarta: Pustaka Rihama.

Hartanto. H. (2010). Keluarga Berencana dan Kontrasepsi. Jakarta: Sinar Harapan.

Makripuddin, L. (2011). Perempuan Unmet Need Index Perdesaan dan Perkotaan. Jogjakarta; Universitas Gadjah Mada.

Madaus, S \& Stufflebeam, et al. (1991). Evaluation Models. Boston: Kluwer-Nij hoff Publishing. 
JPPUMA: Jurnal Ilmu Pemerintahan dan Sosial Politik UMA (Journal of Governance and Political Social UMA), 6 (2) (2018): 122-131.

Malthus. (2007). Kependudukan, Dilema dan Solusi. Bandung: Nuansa.

McConnell. J.V. (1997). Understanding Human Behavior An Introduction to Psychology. $2^{\text {nd }}$ Edition. The United States of America: Rinehart and Winston

Saifudin. (2003). Buku Panduan Praktis Pelayanan Kontrasepsi. Jakarta: Yayasan Bina Pustaka Sarwono Prawirohardjo.

Stake, R,E. (1991). The Case Study Meethod in Social Inquiry. Dalam Madaus, Scriven \& Stufflebeam, hlm. 279-286. Evaluation Models. Boston: Kluwer-Nijhoff Publishing.

Suparman, N. (2017). Kualitas Pelayanan Izin Mendirikan Bangunan (IMB) Pada
Badan Pelayanan Perizinan Terpadu Dan Penanaman Modal Kabupaten Cianjur. Borneo Administrator, 13 (1): 1-88.

-(2017). Evaluasi Kebijkan Pendelagasian Sebagian Wewenang Bupati Kepada Camat di Kecamatan Sagala Herang Subang tahun 2015. Jurnal Politik Indonesia, Vol 2. No. 2: 160-177

Terry, G.R, (1964). Principles of Management Illionis. USA: Richard D. Irwin Inc. Homewood.

Tyler, R.W. (1991). A Rationale For Program Evaluation. Dalam Madaus, Scriven \& Stufflebeam, hlm. 67-78. Evaluation Models. Boston: Kluwer-Nijhoff Publishing. 